\title{
A note on the cyclical behaviour of the income distribution
}

\author{
by \\ Burkhard Heer*
}

\begin{abstract}
Empirically, the income share is procyclical for the low-income groups and acyclical for the top 5\%. To generate this kind of behaviour in a DGE business cycle model, we consider overlapping generations and elastic labour supply in addition to those elements considered by Castañeda et al. (1998). We also analyse a model with rigid wages. However, these features do not help to constitute a major improvement vis-a-vis their model.

JEL classification: C68, D31, E32

Keywords: Income distribution, business cycle, overlapping generations, unemployment, pensions
\end{abstract}

\footnotetext{
* Corresponding author: University of Augsburg, Department of Economics, Universitätsstrasse 16, 86135 Augsburg, Germany, Burkhard.Heer@wiwi.uni-augsburg.de. CESifo, Munich.
} 


\section{Introduction}

Castañeda et al. (1998) document that the US income distribution is highly, but not perfectly procyclical for the low income quintiles, countercyclical for the top 60-95\%, and acyclical for the top $5 \%$. They also present a dynamic general equilibrium model with infinitely-lived agents and unemployment risk that is able to replicate the movements of the lower income quintiles. However, Castañeda et al. fail to replicate the income dynamics of the very rich. In addition, the share of the lowest income quintiles is almost perfectly correlated with real output in their model.

In the next section, we present a simple business cycle model with overlapping generations, elastic labour supply and unemployment. With the assumption of the finite life-time, we are able to introduce more wealth heterogeneity in the model than in the Ramsey-type model of Castañeda et al. (1998). Our aim is to model the dynamics of capital income more accurately. We also consider the potential of pensions to reduce the high negative correlation of the top quintile's income with output found in their model. The top earners in our model are the working households around age 50 when the age-specific productivity attains its maximum and accumulated wealth is close to its peak. With the pensioners, we introduce an income group whose income is not perfectly correlated with output because pensions are not indexed to current wages.

In this model, the almost perfect correlation of the lower income quintiles with output is reduced as the income-rich agents have a more elastic labour supply than the incomepoor. However, the share of the top $5 \%$ of the income earners is almost perfectly negatively correlated with real output. The model and our results are presented in Section 2. Section 3 studies the sensitivity of our results with respect to the introduction of rigid wages. Section 4 concludes.

\section{The model}

\subsection{Households}

Households live 70 periods. Periods are equal to one year. Households are born at age 1 (corresponding to real life-time age 20), and the total mass of the population is equal to 1 . The first 45 periods, households are working, the last 25 periods, they are retired and receive pensions. All agents of age $s$ survive until age $s+1$ with probability $\phi_{s}$, with $\phi_{70}=0$.

Households maximise expected life-time utility at age 1 in period $t$ :

$$
\sum_{s=1}^{70} \beta^{s-1}\left(\prod_{j=1}^{s-1} \varphi_{j}\right) \frac{\left(c_{t+s-1}^{\gamma} 1_{t+s-1}^{1-\gamma}\right)^{1-\eta}-1}{1-\eta},
$$

where $s, c$, and $l$ denote age, consumption, and leisure.

The total time endowment is equal to one and allocated between leisure $l$ and work $n$, $l+n=1$. The worker's labour productivity $e(\varepsilon, z, s)=\varepsilon z e^{\bar{y}_{s}}$ depends on the agent's permanent efficiency type $\varepsilon \in\left\{\varepsilon_{1}, \varepsilon_{2}\right\}$, their idiosyncratic stochastic productivity $z \in\left\{z_{1}, z_{2}\right\}$, 
and their age $s .{ }^{1}$ During working age, $s=1, \ldots, 44$, the process $z_{s}$ follows a Markov chain. If the worker is employed, their total gross labour income, $n_{\mathrm{t}} e(\varepsilon, z, s) w_{t}$, consists of the product of their working time $n_{t}$, their productivity $e(\varepsilon, z, s)$, and the wage per efficiency unit $w_{t}$.

In addition, the household faces the risk of unemployment that is independent of their age $s$, their efficiency type $\varepsilon$, their stochastic productivity $z$, and their previous employment status (employed, unemployed). In a boom (recession), the probability to get unemployed amounts to $\pi^{g}=4 \%\left(\pi^{b}=11 \%\right){ }^{2}$ If the household is unemployed, their leisure is equal to one, $l_{\mathrm{t}}=1$, and they receive unemployment insurance payments $w_{\mathrm{ui}}$ that are constant over the business cycle and independent of their individual productivity $e(\varepsilon, z, s)$. Unemployment insurance is financed by a contribution rate $\tau_{U 1, t}$ on wage income. In old age, agents receive pension payments $b$ that are also constant and are financed by a pension contribution rate $\tau_{b, t}$.

The working agent of age $s$ faces the following budget constraint in period $t$ for age $s=1, \ldots, 45:$

$$
k_{t+1}^{s+1}= \begin{cases}\left(1+r_{t}-\delta\right) k_{t}^{s}+\left(1-\tau_{b, t}-t_{U I, t}\right) n_{t}^{s} e(\varepsilon, z, s) w_{t}-c_{t}^{s} & \text { if employed, } \\ \left(1+r_{t}-\delta\right) k_{t}^{s}+w_{U I}-c_{t}^{s} & \text { if unemployed, }\end{cases}
$$

with $k_{t}^{1} \equiv 0$. Capital $k$ depreciates at the rate $\delta$ and $r_{t}$ denotes the interest rate.

The budget constraint of the retired worker is given by

$$
k_{\mathrm{t}+1}^{s+1}=\left(1+r_{\mathrm{t}}-\delta\right) k_{\mathrm{t}}^{s}+b-c_{\mathrm{t}}^{s}, \mathrm{~s}=46, \ldots, 70,
$$

with $l_{t}^{s}=1$.

\subsection{Production}

Production $Y_{t}$ is characterised by constant returns to scale and assumed to be CobbDouglas:

$$
Y_{t}=A_{t} F\left(K_{t}, L_{t}\right)=A_{t} K_{t}^{\alpha} L_{t}^{1-\alpha} \text {, }
$$

where $L_{t}$ denotes effective labour supply.

Firms are competitive and maximise profits $\Pi_{t}=Y_{t}-r_{t} K_{t}-w_{t} L_{t}$ such that factor prices are given by:

$$
\begin{gathered}
w_{t}=(1-\alpha) A_{t} K_{t}^{\alpha} L_{t}^{-\alpha}, \\
r_{t}=\alpha A_{t} K_{t}^{\alpha-1} L_{t}^{1-\alpha} .
\end{gathered}
$$

\subsection{Equilibrium}

In equilibrium, the following conditions hold:

1. Households maximise their intertemporal utility.

2. In a factor market equilibrium, factors are rewarded with their marginal product presented by (2.1).

3. The budgets of the unemployment insurance and the pension system are balanced in every period $t$. 
4. Individual and aggregate behaviour are consistent. In particular,

$$
\begin{gathered}
L_{\mathrm{t}}=\left(1-\pi_{\mathrm{t}}\right) \sum_{s=1}^{45} \sum_{\varepsilon, \mathrm{z}} e(\varepsilon, \mathrm{s}, \mathrm{z}) \int_{k} n_{\mathrm{t}}^{\mathrm{s}}(k, \varepsilon, \mathrm{s}, \mathrm{z}) \cdot f_{\mathrm{t}}(k, \varepsilon, \mathrm{s}, \mathrm{z}) d k, \\
\mathrm{~K}_{\mathrm{t}}=\sum_{s=1}^{70} \sum_{\varepsilon, \mathrm{z}} \int_{k} k \cdot f_{\mathrm{t}}(k, \varepsilon, \mathrm{s}, \mathrm{z}) d k,
\end{gathered}
$$

where $\pi_{t} \in\left\{\pi^{g}, \pi^{b}\right\}$ and $f_{t}(k, \varepsilon, s, z)$ denote the unemployment rate and the distribution function of the individual state variables in period $t$.

5. The goods market clears.

\subsection{Calibration and computation}

Our survival probabilites are $\phi_{s}$ taken from the United Nations (2002) world population projections. The average life-time of the households amounts to 77.4 years.

We choose the parameter values $\beta=0.99, \eta=2.0, \gamma=0.28, \alpha=0.35$, and $\delta=0.08$ that are standard in the business cycle literature. ${ }^{3}$ Following Krueger and Ludwig (2006), we choose $\left\{\varepsilon_{1}, \varepsilon_{2}\right\}=\{0.57,1.43\},\left\{z_{1}, z_{2}\right\}=\{0.727,1.273\}$, and

$$
\pi\left(z^{\prime} \mid z\right)=\operatorname{Prob}\left\{z_{s+1}=z^{\prime} \mid z_{s}=z\right\}=\left(\begin{array}{ll}
0.98 & 0.02 \\
0.02 & 0.98
\end{array}\right) \text {. }
$$

The age-efficiency $\bar{y}_{s}$ profile is taken from Hansen (1993). Following Storesletten et al. (2007), the aggregate technology level $A_{t} \in\left\{A_{1}, A_{2}\right\}=\{0.98,1.02\}$ follows a 2-state Markov process:

$$
\pi\left(A^{\prime} \mid A\right)=\operatorname{prob}\left\{A_{t+1}=A^{\prime} \mid A_{t}=A\right\}=\left(\begin{array}{cc}
2 / 3 & 1 / 3 \\
1 / 3 & 2 / 3
\end{array}\right) \text {. }
$$

The replacement ratio of pensions and unemployment benefits relative to net wage earnings are both set equal to $30 \%$ with respect to the average steady-state wage income.

The calibration implies an average labour supply approximately equal to $\bar{n}=0.3$ and a Gini coefficient of gross income (wealth) equal to $0.50(0.59)$ in good accordance with empirical observations. ${ }^{4}$

The computation is based upon the algorithm of Krusell and Smith (1998), and follows Storesletten et al. (2007). Furthermore, as we also model endogenous employment, agents have to project effective labour $L^{\prime}$. We find that $L^{\prime}=\exp \left(a_{0}+a_{1} \ln \left(K^{\prime}\right)+a_{2} 1_{A^{\prime}=A_{1}}+a_{3} 1_{A^{\prime}}=A_{1}\right.$ $\left.\ln \left(K^{\prime}\right)\right)$ is a forecasting function with an $R^{2}$ almost identical to one. ${ }^{5}$

\subsection{Results}

Table 1 presents our results. In the first entry row, we display the empirical correlations of output with the $1^{\text {st }}, 2^{\text {nd }}, 3^{\text {rd }}$, and $4^{\text {th }}$ income quintiles, and the $80-95 \%$ and $95-100 \%$ income groups for the US economy, respectively. ${ }^{6}$ In the second row, you find the values resulting from the simulation of the most preferred model of Castañeda et al. (1998). In the last column, we display our performance indicator "Score" which is computed as the sum of the squared deviations between the moments implied by the model and the moments from the data. The third row displays the values obtained from the simulation of our economy with flexible wages as described above. ${ }^{7}$ 
Table 1. Correlation of output with income shares

\begin{tabular}{lccccccc}
\hline & $0-20 \%$ & $20-40 \%$ & $40-60 \%$ & $60-80 \%$ & $80-95 \%$ & $95-100 \%$ & Score \\
\hline US & 0.53 & 0.49 & 0.31 & -0.29 & -0.64 & 0.00 & \\
Castañeda et al. (1998) & 0.95 & 0.92 & 0.73 & -0.56 & -0.90 & -0.84 & 1.38 \\
Our model with flexible wages & 0.92 & 0.85 & 0.94 & -0.93 & -0.86 & -0.92 & 1.98 \\
Our model with rigid wages & 0.85 & 0.89 & 0.90 & -0.32 & -0.88 & -0.88 & 1.44 \\
\hline
\end{tabular}

Notes : Entries in rows 1 and 2 are reproduced from Table 4 in Castañeda et al. (1998). Annual logarithmic output has been detrended using the Hodrick-Prescott filter with smoothing parameter $\lambda=100$. The column Score presents the sum of squared differences between the moments from simulations of the model and the moments from the data.

Even though our model is able to provide a better accordance of the two lowest income share with the empirical data than those in Castañeda et al. (1998), the improvement is only minor. For example, the correlation of the bottom quintile's income with output falls to 0.92 , while it amounts to 0.95 in the model of Castañeda et al. (1998). The total fit as measured by our variable "Score" is much worse and increases from 1.38 to 1.98 . We therefore conclude that our business cycle model of the income distribution with pensions and endogenous labour is not a major improvement over the model of Castañeda et al. (1998).

\section{Rigid wages}

In order to provide more sensitivity analysis to our model, we consider rigid wages in the following. Our interest for the study of this modelling device is motivated by results of the real-business cycle literature on the behaviour of the labour markets in Dynamic Stochastic General Equilibrium models. In particular, we will use the wage equation from Uhlig (2007) who is able to replicate the empirical key characteristics of the US labour market, e.g. the correlations of wages, employment and output, in his model. To this end, we assume that the labour supply of the working agents is inelastic and normalised to one. Total working hours therefore, are equal to the number of employed agents. In each period $t$, a fraction $\pi_{t}$ of the households becomes unemployed. Again, the unemployment probability is independent of individual characteristics such as age, efficiency, or the previous unemployment status. As a consequence, effective labour $L_{t}$ is given by:

$$
L_{t}=\left(1-\pi_{t}\right) \sum_{s=1}^{45} \sum_{\varepsilon, z} e(\varepsilon, s, z) \int_{k} f_{t}(k, \varepsilon, s, z) d k \equiv\left(1-\pi_{t}\right) N_{t} .
$$

Total effective labour demand $L_{t}$ is smaller than effective labour supply $N_{t}$ due to the presence of unemployment.

The friction-free wage $w_{t}^{f}$ in this economy depends on the state of the economy and is equal to the marginal product of effective labour associated with the employment probabilities $1-\pi^{g}$ and $1-\pi^{b}$ in good and bad times, respectively:

$$
w_{t}^{f}= \begin{cases}A_{1} K_{t}^{\alpha}\left(\left(1-\pi^{b}\right) N_{t}\right)^{-\alpha} & \text { bad times : } A_{t}=A_{1}, \\ A_{2} K_{t}^{\alpha}\left(\left(1-\pi^{g}\right) N_{t}\right)^{-\alpha} & \text { good times : } A_{t}=A_{2} .\end{cases}
$$

Let $w_{t-1}$ denote the wage in the previous period $t-1$. Following Uhlig (2007), the wage in period $t$ adjusts only partially to its new friction-free value $w_{t}^{f}$ according to:

$$
w_{t}=\left(w_{t}^{f}\right)^{\mu}\left(w_{t-1}\right)^{1-\mu} .
$$


Therefore, the unemployment probability $\pi_{t}$ only adjusts gradually to its long-run levels $\pi^{g}\left(\pi^{b}\right)$ that would prevail if the economy was permanently in the good (bad) state. As in Uhlig (2007), we set $\mu=0.5$. All other calibrations are as in the previous model.

Our results for the model with rigid wages are summarised in the last row of Table 1. The overall fit as summarised by the variable "Score" improves compared to the case with flexible wages. In particular, the strong pattern of very high correlations of the low income quintiles and almost perfectly negative correlation of the top $40 \%$ income share with output decreases. However, the overall fit is still inferior to that of the model by Castañeda et al. (1998). The Score variable of the model with rigid wages amounts to 1.44 , compared to 1.38 in their model.

\section{Conclusion}

We have found that overlapping generations and the old-age savings motive do not help to improve the understanding of the cyclical income distribution dynamics. Rigid wages are shown to constitute an improvement, however with only small effects. In future research, we are planning to analyse a model with unemployment probabilities that depend upon age and productivity types of the worker. In addition, we conjecture that the introduction of entrepreneurs in the model might help to improve the modelling of the top income quintile dynamics.

\section{Notes}

1. For a more detailed description of the age-efficiency profiles please see Heer and Maussner (2009), Sections 9.3.2 and 10.2.2.

2. The probabilities are set equal to the unemployment rates implied by the ergodic distributions in Castañeda et al. (1998).

3. See, for example, Heer and Maussner (2009).

4. The Gini coefficient of wealth falls somewhat short of empirical values because we do not consider bequests, borrowing constraints, and entrepreneurship.

5. The Gauss computer program is available from the author upon request.

6. The estimates are reproduced from Table 4 in Castañeda et al. (1998). In all computations presented in Table 1, log income has been detrended using the Hodrick-Prescott filter with smoothing parameter $\lambda=100$.

7. We have also experimented with a CES production function that is not Cobb-Douglas and with pensions, and unemployment benefits that are proportional to the efficiency types of the workers. However, the fit did not improve.

\section{References}

Castañeda, A., J. Díaz-Giminénez and J.-V. Ríos-Rull (1998), "Exploring the Income Distribution Business Cycle Dynamics", Journal of Monetary Economics, Vol. 42, pp. 93-130.

Hansen, G. (1993), "The Cyclical and Secular Behavior of the Labor Input: Comparing Efficiency Units and Hours Worked", Journal of Applied Econometrics, Vol. 8, pp. 71-80.

Heer, B. and A. Maussner (2009), Dynamic General Equilibrium models: Computational Methods and Applications, 2nd ed., Springer-Verlag, Berlin.

Krueger, D. and A. Ludwig (2006), "On the Consequences of Demographic Change for Rates of Returns to Capital, and the Distribution of Wealth and Welfare", Journal of Monetary Economics, Vol. 54, pp. 49-87.

Krusell, P. and A. Smith (1998), "Income and Wealth Heterogeneity in the Macroeconomy", Journal of Political Economy, Vol. 106, pp. 867-96. 
Storesletten, K., C.I. Telmer and A. Yaron (2007), “Asset Pricing with Idiosyncratic Risk and Overlapping Generations", Review of Economic Dynamics, Vol. 10, pp. 519-548.

Uhlig, H. (2007), "Explaining Asset Prices with External Habits and Wage Rigidities in a DSGE model", American Economic Review, Papers \& Proceedings, Vol. 97, pp. 239-43.

United Nations (2002), World Population Prospects: The 2002 Revision, United Nations Population Division, United Nations, New York. 


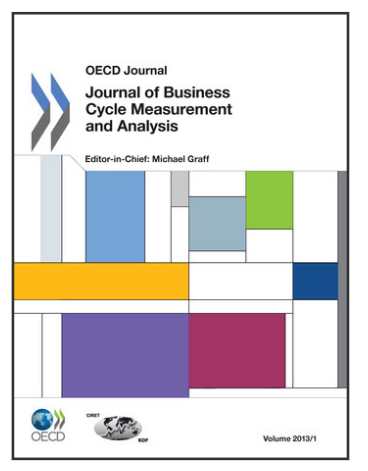

\section{From: \\ OECD Journal: Journal of Business Cycle Measurement and Analysis}

Access the journal at:

https://doi.org/10.1787/19952899

\section{Please cite this article as:}

Heer, Burkhard (2013), "A note on the cyclical behaviour of the income distribution", OECD Journal: Journal of Business Cycle Measurement and Analysis, Vol. 2013/1.

DOI: https://doi.org/10.1787/jbcma-2013-5k483456blbr

This work is published under the responsibility of the Secretary-General of the OECD. The opinions expressed and arguments employed herein do not necessarily reflect the official views of OECD member countries.

This document and any map included herein are without prejudice to the status of or sovereignty over any territory, to the delimitation of international frontiers and boundaries and to the name of any territory, city or area.

You can copy, download or print OECD content for your own use, and you can include excerpts from OECD publications, databases and multimedia products in your own documents, presentations, blogs, websites and teaching materials, provided that suitable acknowledgment of OECD as source and copyright owner is given. All requests for public or commercial use and translation rights should be submitted to rights@oecd.org. Requests for permission to photocopy portions of this material for public or commercial use shall be addressed directly to the Copyright Clearance Center (CCC) at info@copyright.com or the Centre français d'exploitation du droit de copie (CFC) at contact@cfcopies.com. 